LÓPEZ-RUIZ Víctor-Raúl, HUETE-ALCOCER Nuria, ALFARO-NAVARRO José-Luis, NEVADO-PEÑA Domingo

\title{
TOWARDS A MODEL OF HAPPINESS AND QUALITY OF LIFE IN SPANISH SOCIETY
}

In Happiness And Contemporary Society : Conference Proceedings Volume (Lviv, March, 20-21, 2021). Lviv: SPOLOM, 2021. P. 168-170. https://doi.org/10.31108/7.2021.38

ISBN 978-966-919-697-2 
https://doi.org/10.31108/7.2021.38

LÓPEZ-RUIZ Víctor-Raúl

Professor in Econometrics, University of Castilla-La Mancha (Albacete, Spain)

HUETE-ALCOCER Nuria

Assistant Professor in Econometrics, University of Castilla-La Mancha (Albacete, Spain)

ALFARO-NAVARRO José-Luis

Professor in Statistics, University of Castilla-La Mancha (Albacete, Spain)

NEVADO-PEÑA Domingo

Professor in Accountancy, University of Castilla-La Mancha (Ciudad Real, Spain)

\section{TOWARDS A MODEL OF HAPPINESS AND QUALITY OF LIFE IN SPANISH SOCIETY}

The pursuit of well-being is the key objective for the whole society, as it leads to the happiness of the individual, becoming a key factor from a social economic perspective. Among the dimensions fixed by social individuals, the place of residence is an essential aspect, since it affects all aspects of their daily life, together with the conditions and work development. In this sense, this study analyzes the degree of satisfaction of Spanish citizens in aspects of their quality of life, in residence and work environments, which therefore induce their happiness. On the one hand, those related to the living environment; and on the other, to the work and training environment. The effect of the COVID-19 pandemic on their quality of life has also been analysed. The data were collected through an online questionnaire in the summer of 2020, the total sample obtained being representative of 933 responses.

KEYWORDS: happiness, quality of life, wellness, pandemic

\section{INTRODUCTION}

In the urban and community sphere, the quality of life of citizens has become an essential element of politics in most of the countries of the European Union (WęziakBiałowolska, 2016). Satisfaction with life is a subjective assessment of quality of life in general and is the indicator that leads to subjective well-being (Baum, Arthurson and Rickson, 2010; Cuñado and Gracia, 2013), considered as a synonym of happiness when it refers to how people feel and think about their lives (Diener et al., 1985; Diener, 2000; Cuñado and Gracia, 2013). Currently, life satisfaction and happiness are highly researched topics in social sciences, psychology, philosophy, and economics (Lu et al., 2020).

Thus, the purpose of this study has been to know how issues related to the living environment affect happiness (family situation, trust, environment, commercial accessibility and public transport, green areas, culture and sports, foreign population, health, education, price of housing and security); the work and training environment (economic and employment situation, work environment, training, internet access); and finally, what effects have occurred due to the COVID-19 pandemic on the quality of life and in the family and work environment of the respondents. We also draw a set of conclusions on how the happiness of the individual is affected according to their sociodemographic characteristics (gender, place of residence, age, productive sector). 
For the analysis, we have the opinion of 933 Spaniards, through an online questionnaire developed by the Intangibles and Quality of Life Observatory in the summer of 2020.

\section{METHODOLOGY AND DATA}

The tabulation method chosen was with a 10-point Likert scale (1 being "not at all satisfied" to 10 "very satisfied") on the degree of satisfaction of citizens in some aspects of the quality of life in their place of residence and work, related to the different dimensions that affect the achievement of their happiness, according to different previous analyses by academics. Some questions related to COVID-19 and its effect on quality of life were also included. The data collection was carried out between July 2 and September 8, 2020, through an online questionnaire, distributed mostly by email and social networks, the sample obtained being 933 responses, which represents an estimation error. $3.2 \%$ at a $95 \%$ confidence level.

\section{RESULTS AND CONCLUSIONS}

The analysis of this work has allowed us to know how happiness affects its sociodemographic characteristics (gender, place of residence, age, productive sector), to be able to discriminate the results by groups and compare various situations. Issues related to the living environment, work environment and training have been included; and finally, on the effects of the pandemic.

Regarding sociodemographic characteristics, the results of the survey have shown how women are happier than men in terms of satisfaction with life.

On the other hand, regarding the place of residence, four intervals were established to classify it. Thus, it can be verified that of the citizens who responded to the questionnaire, 45.3\% resided in large cities, (with more than 100,000 inhabitants), followed by the section between 5,001 and 100,000, accumulating between both sections $84.3 \%$ of the shows. Later, with this classification, it can be determined whether citizens are happier in urban areas or rural areas (towns). Taking the average, the ideal place to reside in terms of happiness in Spain are municipalities with 1,000 to 5,000 inhabitants, where there is greater security and less effect of the pandemic. In addition, the North-South geographical category does affect, with higher levels of life satisfaction in the northern area.

On the other hand, to analyse the influence of age on the happiness of the respondents, seven age groups were organized. Happiness has significant differences by age, and it is concluded that the happiest people are those who are older, from the age of 60 . This may show that the age at the beginning of the work activity influences people's happiness.

It was also considered to analyse the economic sector of the citizen's activity. In these terms, it can be clearly seen that it is the unemployed or inactive who present the least happiness, followed by those employed in communication services and tourism, undoubtedly one of the sectors most affected by the current pandemic. On the contrary, it is those employed in the manufacturing sector, in commerce and the primary sector, in that order, who achieve the highest levels of happiness.

In relation to the characteristics of the living environment, the results obtained in the survey were that $72.8 \%$ of citizens are very satisfied with their life and place of residence and approximately $72.3 \%$ with their family situation.

On the other hand, if we consider the averages reached, with a maximum of 10 , the satisfaction of citizens can be assessed in relation to the confidence of living in their neighbourhood, the value being 7.22 points; 7.09 in the value about the environment in terms of air quality, noise, cleanliness; 7.1 points on access to commercial services and 
public transport; 7.2 in relation to the green spaces available; 7.3 in access to culture and sports; 6.6 with the integration of the foreign population; In terms of health infrastructures: hospitals and health centres, the average was 7.52 points; on available educational offer, affects the size of the population with 7.34 in large cities, while in rural areas it has an interval between 6 and 6.5 points. Regarding satisfaction with house prices, an average of 5.91 points was barely obtained, constituting an undoubted criticism of the high prices of the Spanish system. However, security at the place of residence reaches a higher score of 8.03.

On the other hand, regarding the work and / or training environment, the economic situation of the respondents was assessed, where an average of 7.2 points was obtained when they were asked if they were satisfied with their economic compensation for the work performed. However, the average is lower, specifically 6.34 points when they valued their happiness in their job and higher, 8.33 points in satisfaction with the work environment. Regarding the relationship between the happiness of citizens and training in the job, the average satisfaction was barely 6.52 points. Another factor on the rise in happiness has been connectivity, where the average obtained of 7.78 points shows, a total of $90 \%$ of those surveyed, how important this service is, and especially its security in private environments and business (90\%), very favourable for teleworking, although it is with the worst score in rural areas.

Finally, in this study, the effects of the COVID-19 pandemic on the quality of life of Spanish citizens are assessed. $73.5 \%$ of those surveyed stated that the effects were negative on their quality of life. It can also be seen that, of the total sample, 39.4\% indicated that it had affected them more in their personal environment and $38.4 \%$ in their work environment, the surprising thing is that even more than $20 \%$ confessed not feel affected.

From the Observatory of Intangibles and Quality of Life, we work on a model that relates the main dimensions of quality of life, measuring their importance, and establishing a dynamic and comparative comparison (Romania).

\section{REFERENCES}

1. Baum, S., Arthurson, K., \& Rickson, K. (2010). Happy people in mixed-up places: The association between the degree and type of local socioeconomic mix and expressions of neighbourhood satisfaction. Urban Studies, 47(3), 467-485.

2. Cuñado, J., \& De Gracia, F. P. (2013). Environment and happiness: New evidence for Spain. Social Indicators Research, 112(3), 549-567.

3. Diener, E. D., Emmons, R. A., Larsen, R. J., \& Griffin, S. (1985). The satisfaction with life scale. Journal of personality assessment, 49(1), 71-75.

4. Diener, E. (2000). Subjective well-being: The science of happiness and a proposal for a national index. American psychologist, 55(1), 34.

5. Lu, H., Tong, P., \& Zhu, R. (2020). Longitudinal evidence on social trust and happiness in China: Causal effects and mechanisms. Journal of Happiness Studies, 21(5), 1841-1858.

6. OICV (2020): Felicidad y Calidad de Vida de los españoles. Informe 1. Semestre II. Available in: https://blog.uclm.es/victorlopez/files/2020/10/informe-felicidad-22-102020.pdf

7. Węziak-Białowolska, D. (2016). Quality of life in cities-Empirical evidence in comparative European perspective. Cities, 58, 87-96. 